\title{
JUDICIALIZAÇÃO DAS PRÁTICAS TRABALHISTAS: A QUESTÃO DA PEJOTIZAÇÃO NA JURISPRUDÊNCIA DO TRT-1
}

\author{
JUDICIALIZATION OF LABOR PRACTICES: THE QUESTION OF \\ PEJOTIZATION (INDEPENDENT-CONTRACTOR-ONLY HIRING POLICY) \\ IN THE TRT-1 JURISPRUDENCE
}

\author{
Felipe Dutra Asensi \\ Universidade do Estado do Rio de Janeiro - UERJ - (Rio de Janeiro, RJ, Brasil) \\ Isabela Pfister Gonçalves \\ Universidade Santa Úrsula (Rio de Janeiro, RJ, Brasil) \\ Recebimento: 15 fev. 2019 \\ Aceitação: 22 abr. 2019
}

\begin{abstract}
Como citar este artigo / How to cite this article (informe a data atual de acesso / inform the current date of access):
ASENSI, Felipe Dutra; GONÇALVES, Isabela Pfister. Judicialização das práticas trabalhistas: a questão da pejotização na jurisprudência do TRT-1. Revista da Faculdade de Direito UFPR, Curitiba, PR, Brasil, v. 64, n. 1, p. 165-186, jan./abr. 2019. ISSN 2236-7284. Disponível em: <https://revistas.ufpr.br/direito/article/view/64979>. Acesso em: 30 abr. 2019. DOI: http://dx.doi.org/10.5380/rfdufpr.v64i1.64979.
\end{abstract}

\section{RESUMO}

A pejotização se refere à situação na qual o empregado precisa constituir uma pessoa jurídica (PJ) a fim de que a sua contratação aconteça. Com isso, o contrato instituído é de prestação de serviços, e não de trabalho, o que resulta para o empregador no desencargo do pagamento de todos os direitos trabalhistas que estariam presentes se a contratação ocorresse mediante o reconhecimento do vínculo empregatício. Esta pesquisa estuda a pejotização no direito do trabalho por meio da análise de 402 decisões tomadas pelo Tribunal Regional do Trabalho da $1^{\text {a }}$ Região (TRT-1) entre os anos de 2010 e 2017, coletadas no banco de dados desse tribunal, bem como analisa os argumentos que mobilizaram os julgadores na formação de suas decisões. A contratação pejotizada tem sido objeto de muita demanda judicial, já que o empregado, ao término da execução dos serviços, busca a prestação jurisdicional na pretensão de ver reconhecido o vínculo de emprego, de modo a receber os valores referentes aos direitos trabalhistas então suprimidos. Os resultados apontam que a pejotização, mesmo após a reforma trabalhista, continua sendo julgada pelo TRT-1 como fraude à relação laboral, pois a imposição da constituição de PJ enquanto requisito essencial para contratação objetivaria, ao empregador, esquivar-se das obrigações de pagamento de encargos sociais e trabalhistas relativos ao empregado.

\section{PALAVRAS-CHAVE}

Pejotização. Decisões judiciais. Reforma trabalhista.

\section{ABSTRACT}

Pejotization refers to an independent-contractor-only policy in which the employee needs to constitute a legal entity (Pessoa Jurídica, or PJ, hence the name) in order for its hiring to take place. As a result, the employee is meant to provide services, not work, which results to the employer in the non-obligation of the payment of all labor rights that would be present if the hiring had occurred 
through the recognition of the normal employment relationship. This research studies pejotization in labor law through the analysis of 402 decisions taken by the Regional Labor Court of the 1st Region (TRT-1) between 2010 and 2017, collected in the database of this court, as well as the arguments that mobilized the judges in shaping their decisions. Pejotization has been the subject of a lot of judicial demand since the employee, at the end of the execution of the services, seeks the jurisdictional provision in the claim to see the normal employment bond recognized, so as to receive the values referring to the labor rights then abolished. The results indicate that pejotization, even after the labor reform, continues to be judged by the TRT -1 as a fraud to the employment relationship, since the imposition of the constitution of a $P J$ as an essential requirement for contracting aims to avoid the payment, by the employer, of social and labor charges related to the employee.

\section{KEYWORDS}

Pejotization. Judicial decisions. Labor reform.

\section{INTRODUÇÃO}

Com o advento da Constituição de 1988 e a redemocratização do País, o legislador “elevou uma pluralidade de direitos à condição de normas constitucionais” (ASENSI et al., 2015, p. 4), direcionando ao Poder Judiciário o ofício de assumir alguns papéis para a sua efetivação. Assim, dentre as mais variadas incumbências do Judiciário, coube também a este Poder zelar pela democracia por meio de ações que pudessem ampliar o acesso dos cidadãos à justiça. Assegurar que todo cidadão usufrua de um provimento jurisdicional é um dos alicerces de sustentação do ordenamento jurídico, pois torna legítimo o atuar das instituições jurídicas diante da efetivação dos direitos. Diante deste cenário, o Poder Judiciário figura como um dos responsáveis institucionais pela preservação do Estado Democrático de Direito, assim como pela convivência jurídica entre a sociedade e o Estado.

Esta condição de implementar e efetivar os direitos é o que fez surgir a judicialização, que se trata de um processo no qual os magistrados são provocados frequentemente a solucionar demandas e conflitos políticos e sociais. Na judicialização, o Poder Judiciário exerce função protagonista a fim de efetivar os direitos, em especial os direitos sociais e coletivos, o que resulta na “atuação do poder judiciário sobre o poder político” (VIANNA, 2003, p. 11). Também passou a ser depositada no Judiciário a expectativa de os cidadãos creditarem a sua expectativa a fim de verem protegidos, resguardados e garantidos os seus direitos. Portanto, observa-se que a judicialização conferiu uma "nova indumentária” ao Judiciário, pois passou a exercer função essencial na sociedade moderna ao se tornar um intermediário ativo para a promoção de políticas públicas que venham efetivar direitos coletivos e sociais.

No âmbito trabalhista, a judicialização tem sido essencial para defesa dos direitos sociais dos trabalhadores, pois tem trazido efeitos na relação entre empregado e empregador sob diversas 
dimensões. Observa-se que judicializar relações sociais tornou o Poder Judiciário um veículo eficaz para solução de litígios laborais, daí as razões pelas quais ele tem figurado como opção de resolução de conflitos, inclusive nos casos da chamada pejotização.

A pejotização ocorre quando a contratação de um trabalhador acontece na condição de pessoa jurídica, o que proporciona para o empregador a desobrigação de anotação da carteira profissional do empregado, eximindo-o assim das obrigações inerentes ao pagamento das verbas trabalhistas, tais como o décimo terceiro salário, as férias, o descanso semanal remunerado, os depósitos do fundo de garantia por tempo de serviço e todos os demais encargos sociais. Mesmo com toda a relevância que há na oferta de vagas no mercado de trabalho para crescimento e sustentação da economia do mercado capitalista, a questão da pejotização vem sendo discutida de maneira cada vez mais consistente quando analisados os efeitos que esta produz no contrato de trabalho.

No Rio de Janeiro, segundo dados do Tribunal Regional do Trabalho da $1^{a}$ Região, mais de 80\% das formas de contratação pejotizada é fraudulenta ou prejudicial ao empregado. A definição versada por Marcondes e Naomi acerca da pejotização a associa à figura de "um método fraudulento que visa mascarar uma contratação a fim de desobrigar-se dos encargos comuns do contrato de trabalho” (MARCONDES; NAOMI, 2015, p. 2). Assim, a contratação pejotizada pode ser uma forma de se esquivar à contratação tradicional do empregado ao eventualmente "mascarar" os resultados desse pacto laboral mediante um ganho salarial maior que, a priori, pode parecer mais vantajoso.

Portanto, realizar uma análise do entendimento do Judiciário acerca da pejotização tornase de relevante interesse científico, pois permite analisar como se desenvolve a relação entre empregador e empregador e as concepções e práticas do Judiciário no que concerne a esta forma de contratação. Empresas, empregadores, sociedade, mercado e até mesmo governos são beneficiados pelos debates sobre a pejotização e seus impactos.

Esta pesquisa analisará qual a jurisprudência do Tribunal Regional do Trabalho da $1^{\text {a }}$ Região diante da pejotização e os argumentos mobilizados pelos julgadores a fim de embasar suas decisões. A questão norteadora da pesquisa buscará investigar a seguinte indagação: Qual o entendimento do TRT-1 acerca da legalidade da pejotização entre os anos de 2010 a 2017? O objetivo geral desta pesquisa consiste em analisar como o TRT-1 se posiciona quanto à questão da pejotização nos anos de 2010 a 2017 e se o seu posicionamento se transforma ou não com a Reforma Trabalhista. Também se busca analisar os argumentos mobilizados por juízes na apreciação de demandas judiciais sobre a pejotização e a tendência decisória desse Tribunal. 
No próximo capítulo, será discutida a judicialização do direito do trabalho, a fim de refletir sobre a pejotização e a busca pela prestação jurisdicional num prisma de proteção ao trabalhador. No capítulo seguinte, são analisadas as decisões emanadas no âmbito do TRT-1 quanto à pejotização, sob o prisma das quatro categorias analíticas desta pesquisa: a vulnerabilidade do trabalhador, a violação ao princípio da primazia da realidade, a caracterização do vínculo empregatício e a caracterização da fraude trabalhista. Por fim, a título de considerações finais, serão discutidos os resultados da pesquisa e apontados alguns caminhos e possibilidades de alteração do entendimento jurisprudencial em função da reforma trabalhista.

\section{TRABALHO E DIREITO NO BRASIL}

\subsection{JUDICIALIZAÇÃO DO DIREITO DO TRABALHO}

Historicamente, o Poder Judiciário se manteve “tímido” ante a mudança social e exerceu pouco protagonismo. Trata-se daquela velha premissa de que só poderia se manifestar se provocado e, ainda assim, submetido à condição de mero reprodutor do contexto legal previsto. Essa posição de poder inerte atualmente apresenta uma mudança significativa, haja vista a função do Judiciário de transformar aqueles direitos que são unicamente expressos em efetivamente possíveis de serem usufruídos por seus beneficiários. Segundo Vianna, Carvalho, Melo e Burgos, “no cenário moderno, o que se verifica é a modificação do denominado poder inerte a um “terceiro poder 'gigante’ [...] o que torna o juiz protagonista direto da questão social” (VIANNA et al., 1999, p. 39).

Nessa linha, os autores denominam como judicialização o termo que define o movimento de discussão, no campo do direito, dos conflitos político-sociais. Parte-se do princípio de que o Judiciário, "provocado adequadamente, pode ser um instrumento de formação de políticas públicas” (DALLARI et al., 1996), o que confere a esta instituição centralidade no âmbito da garantia de direitos. Tal perspectiva exprime que não somente os atores privilegiados, tais como partidos políticos, chefes do Executivo, etc. se utilizam da via judicial para resolver conflitos políticos. Judicializar relações sociais envolve um processo muito mais amplo, que alça o Judiciário a referencial de resolução de conflitos sociais. Os autores salientam que essa perspectiva consiste num

conjunto de práticas e de novos direitos, além de um continente de personagens e temas até recentemente pouco divisável pelos sistemas jurídicos [...], os novos objetos sobre os quais se debruça o Poder Judiciário, levando a que as sociedades contemporâneas se vejam, cada vez mais, enredadas na semântica da justiça. É, enfim, a essa crescente invasão do direito na organização da vida social que se convencionou chamar de judicialização das relações sociais (VIANNA et al., 1999, p. 149). 
Mas, de fato, ao que alguns estudiosos da judicialização atribuem essa transformação do Judiciário no mundo contemporâneo? Quais são os fatores associados à judicialização da vida atualmente e quais os limites e desafios que se apresentam diante desse processo, principalmente na saúde?

Neil Tate e Tobjörn Vallinder (1995) dedicam reflexões interessantes sobre o tema. O fenômeno da judicialização da política, na visão dos autores, pressuporia a existência de algumas condições, quais sejam: a) a existência de um ambiente fortemente democrático e, como desdobramento deste; b) a separação dos Poderes estatais; c) a política de direitos dos cidadãos; d) o uso das cortes pelos grupos de interesses; e) o uso das cortes pelas oposições; f) as instituições majoritárias não efetivas; g) a legitimação do Judiciário enquanto uma instituição policy-maker; h) a delegação (consciente ou não) das instituições majoritárias ao Judiciário.

Nesse sentido, a condição sine quad non para a formação e intensificação da judicialização da política e das relações sociais seria a presença de um ambiente democrático em que as instituições do Estado Democrático de Direito, apesar de separadas e mantidas em sua autonomia administrativa, funcional e política, criariam seus próprios mecanismos de interpenetração e controle mútuos.

No Brasil, como já discutido, “a visão clássica dos tribunais como instâncias estritamente legais tem sido contestada pelas crescentes evidências de seu papel político e de seu impacto diário nas políticas públicas.” (TAYLOR, 2007, p. 229). Desse modo, não só as relações sociais e políticas têm sido cotidianamente submetidas ao crivo deste Poder, mas também, em função de sua independência funcional, as relações entre Estado e sociedade, sobretudo os direitos sociais.

Taylor observa, em recente pesquisa, que "nem toda proposta do governo foi contestada judicialmente, mas as mais importantes e contenciosas certamente o foram, e com algum sucesso" (TAYLOR, 2007, p. 237). A judicialização é um meio pelo qual relevantes demandas sociais e políticas são solucionadas pelo Judiciário. Segundo Asensi et al., a judicialização conduziu ao:

\footnotetext{
surgimento do protagonismo do judiciário na efetivação de direitos, principalmente de cunho social e coletivo. Neste sentido, o cidadão se voltaria ao judiciário como estratégia e mobilização de recursos e argumentos para a defesa e conquista de direitos. Um sentido bastante simples da ideia de judicialização da política diz respeito ao papel que o judiciário passou a desempenhar nas sociedades contemporâneas como agente ativo na implementação de políticas públicas e efetivação de direitos. (ASENSI et al., 2015, p. 5).
}

Portanto, na prática, a judicialização pode ocorrer quando os cidadãos buscam com alguma frequência o Poder Judiciário como veículo de defesa e obtenção de direitos, o que alça esse Poder à condição de órgão competente para resolução de conflitos sociais. E isso quer dizer que, ao 
judicializar as relações sociais, as consequências atingidas podem ser muito mais amplas em termos sociais, o que conduz o Judiciário a se tornar até mesmo um protagonista em diversos direitos.

A expansão do Judiciário, segundo Vianna, Burgos e Salles, nada mais é do que "a invasão do direito sobre o social que avança na regulação dos setores mais vulneráveis em um claro processo de substituição do Estado e dos recursos institucionais classicamente republicanos pelo judiciário”. (VIANNA; BURGOS; SALLES, 2006, p. 41). Em decorrência desta tendência, a posição do Judiciário tem se tornado cada vez mais uma via para a solução de questões políticas e sociais.

Quanto à judicialização do direito do trabalho, ela é observada com frequência, já que vários direitos dos empregados são muitas vezes suprimidos e a resolução da questão pelas vias negociais pode ter dificuldades estruturais, econômicas e culturais.

Deve-se considerar que a judicialização do direito do trabalho também pode ocorrer por conta da eventual desigualdade ou assimetria nas negociações diretas entre empregado e empregador. E isso quer dizer, em outros termos, que "reforça o processo de controle do conflito de classe diante da relação capital-trabalho” (MANDL, 2014, p. 304). Não é novidade que as demandas trabalhistas tiveram grande crescimento a cada novo ano e suas causas podem estar associadas à supressão de direitos dos empregados que são violados mediante manobras contratuais praticadas pelo empregador, como no caso da pejotização.

\subsection{A PROTEÇÃO DO TRABALHADOR E A CONTRATAÇÃO PEJOTIZADA}

Um dos objetivos do direito do trabalho é promover melhorias nas condições de trabalho e também proporcionar um bom relacionamento entre empregado e empregador. Miguel Reale, versando sobre a questão, afirma que:

realçando a finalidade do direito como sendo a manutenção da ordem social, é imperiosa a existência de um conjunto de normas jurídicas que disciplinem a vida em sociedade, impondo limites, critérios de ação quanto às relações humanas. A estrutura da norma jurídica é do tipo dever-ser. Procura disciplinar atitudes, comportamentos, ações e omissões do homem em sociedade, de forma preventiva. Portanto, o Direito do Trabalho reflete a visão humanista do próprio Direito nas relações sociais, cujo objeto é o trabalho humano subordinado. (REALE, 2011, p. 115).

Portanto, o direito do trabalho busca proporcionar uma composição justa e equivalente às partes, a fim de que venha satisfazer a todos os envolvidos e preservar o equilíbrio da relação laboral. Esse direito também busca promover a igualdade, uma vez que o trabalhador é a parte mais vulnerável na relação e, para tanto, está embasado em princípios e normas protetoras, tais como o princípio da 
proteção, o princípio da norma mais favorável, o princípio da condição mais benéfica e o princípio da continuidade da relação de emprego.

O princípio da proteção do trabalhador objetiva proporcionar acolhimento ao empregado independentemente se esta é ou não a sua vontade, tendo em vista a premissa de vulnerabilidade presente no direito do trabalho. Observa-se que este princípio nada mais é do que o próprio fundamento do direito laboral, que busca proteger a parte mais fraca da relação em decorrência da desigual capacidade econômica.

O princípio da norma mais favorável determina que, havendo duas ou mais normas trabalhistas, sejam aplicadas aquelas que trazem ao trabalhador maiores benefícios, tendo em vista a premissa da hipossuficiência técnica presente no direito do trabalho.

O princípio da condição mais benéfica determina que as condições mais favoráveis previstas no contrato laboral devem ser aplicadas em detrimento de outras menos favoráveis, sendo, então, indesejável qualquer supressão, modificação ou redução inferior àquela já pactuada na formação do vínculo empregatício. Conforme Alice Monteiro de Barros, o princípio da condição mais benéfica busca "proteger situações pessoais mais vantajosas que se incorporam ao patrimônio do empregado, por força do próprio contrato, de forma expressa ou tácita consistente esta última em fornecimentos habituais de vantagens que não poderão ser retiradas” (BARROS, 2015, p. 170). Assim, observa-se que este princípio intenta garantir ao trabalhador a fixação dos direitos mais vantajosos durante a vigência do contrato de trabalho.

Por fim, o princípio da continuidade da relação de emprego prevê o dever do direito do trabalho de preservar a permanência do vínculo empregatício, afinal, o labor é um direito fundamental de todos. Observa-se que este princípio confere um forte suporte argumentativo para defesa do trabalhador no que concerne à permanência do vínculo.

Vale citar que o trabalhador, por ser a parte economicamente mais vulnerável na relação, faz jus à proteção estatal por meio dos princípios mencionados. E essa proteção objetiva, conforme analisado, equilibrar a desigualdade econômica que pode desfavorecer o trabalhador.

Paralela a esta proteção do trabalhador prevista na Consolidação das Leis do Trabalho (CLT; Decreto-Lei n. ${ }^{\circ}$ 5.452/1943) e na Constituição de 1988, a pejotização ocorre quando o empregador exige que o empregado constitua pessoa jurídica (PJ) para que sua contratação aconteça. Ou seja, para que o trabalhador ocupe a vaga que está disponível na empresa, é necessário que este constitua uma PJ para que não haja um contrato de trabalho com pessoa física, mas sim um contrato de prestação de serviço com pessoa jurídica. Por isso, quando se fala em pejotização, são discutidas as normas protetoras do direito do trabalho e as garantias já conquistadas pelos trabalhadores. 


\section{A PEJOTIZAÇÃO NO ENTENDIMENTO DO TRT-1}

\subsection{ESTRATÉGIA METODOLÓGICA}

Trata-se, o presente trabalho, de pesquisa quantitativa e qualitativa, com foco na análise documental. Por ser quantitativa, valeu-se de método no qual se fez uso de dados estatísticos com a finalidade de quantificar e demonstrar posicionamentos, opiniões e entendimentos dos julgadores do TRT-1 no período histórico de 2010 a 2017. A parte qualitativa se valeu das percepções dos julgadores acerca do objeto investigado, em que se buscou também entender, explicar e descrever o posicionamento da jurisprudência do TRT-1. Cabe frisar que como o foco é a jurisprudência do TRT-1 e os argumentos são mobilizados para fundamentar as posições sobre a pejotização, analisouse também comparativamente as decisões de antes e depois da reforma trabalhista.

Para a realização desta pesquisa, foram coletados, no sítio virtual do TRT-1, as decisões pertinentes à palavra “pejotização” entre os anos de 2010 e 2017, tendo como base as reclamações trabalhistas do período, em sede de recurso, ao Tribunal. Mais precisamente, os dados foram coletados na seguinte sequência: ícone “jurisprudência”, que conduziu a outro ícone denominado de “consultar acórdãos”, que remeteu a um outro subitem denominado de “pesquisa livre”. No campo “pesquisa livre” foi inserida a palavra-chave “pejotização”, cujo resultado foi de 505 decisões.

Das 505 decisões, 402 eram de 2010 a 2017 e 103 eram do ano de 2018. Dentre as do ano de 2018, foram selecionadas as 20 primeiras e desprezadas as 83 restantes, pois o período histórico analisado é de 2010 a 2017. Quanto a isso, é importante esclarecer que somente se fez uso dessas 20 decisões de 2018 porque a chamada Reforma Trabalhista, instituída pela Lei ${ }^{\circ}$ 13.467/2017, entrou em vigor em 11 de novembro de 2017, e desta data até o recesso judicial não foram encontradas decisões sobre pejotização.

As 422 decisões (402 de 2010 a 2017 e 20 de 2018) foram agrupadas em quatro categorias analíticas principais, que são os argumentos mais mobilizados pelos desembargadores no embasamento de suas decisões. Essas categorias são as seguintes: a configuração do contrato de trabalho, a violação ao princípio da primazia da realidade e a vulnerabilidade do trabalhador, a caracterização da fraude trabalhista. Tais categorias foram escolhidas porque constituem os argumentos observados com maior incidência nas decisões, ou seja, foram as alegações principais que mobilizaram os desembargadores. Elas são importantes porque permitem identificar a existência de vínculo empregatício na relação contratual quando esta encontra-se “mascarada” pela pejotização. 
Todavia, vale mencionar que também foram analisadas outras razões que igualmente fundamentaram as decisões, até mesmo para que essas razões possam figurar nos dados estatísticos. Algumas decisões também foram fundamentadas esporadicamente no princípio da irrenunciabilidade, que prescreve que é vedado ao empregado, mesmo que seja este o seu desejo, abrir mão ou renunciar aos seus direitos que decorrem da relação trabalhista. Nas decisões que são fundamentadas mediante esse princípio, os julgadores argumentaram que é defeso ao trabalhador furtar-se por livre vontade dos benefícios que lhe são ofertados ante o vínculo de trabalho. Com esta premissa, os julgadores argumentaram que a pejotização seria ilegal porque o trabalhador não disporia da facultatividade de se privar dos seus direitos laborais. Em outras decisões, o reconhecimento da contratação pejotizada foi negado sob o argumento de não havia caracterização do vínculo diante da presente liberdade para execução do serviço e, portanto, inexistência de forma de subordinação ou exclusividade na prestação do serviço.

Vale citar que a pesquisa está restrita aos litígios apresentados no segundo grau de jurisdição. Nos dados, a pejotização majoritariamente é entendida como fraude trabalhista pelo juízo a quo e a incidência recursal é absolutamente frequente, sendo então a demanda enviada ao juízo ad quem.

Por fim, é importante ressaltar que a análise das decisões foi estruturada em três momentos. No primeiro deles, foi realizada uma exposição geral de cada categoria analisada, explicando-a separadamente e apontando em que situações ela pode ser observada; no segundo, foram analisados os argumentos apregoados pelo julgador, destacando as percepções sobre a pejotização; no terceiro, foram apresentados os dados, separados por período histórico, a fim de compreender melhor os resultados e explicá-los.

\subsection{CONFIGURAÇÃO DO VÍNCULO EMPREGATÍCIO}

Configura-se vínculo empregatício sempre que se verificar na relação os requisitos de subordinação, pessoalidade, onerosidade e habitualidade, conforme preceitua o artigo $3^{\circ}$ da CLT. A subordinação é um dos elementos mais relevantes na configuração do contrato de trabalho, tanto que a jurisprudência é uniforme em assim reconhecê-la, pois consiste na prestação do serviço por parte do trabalhador sob a direção e gerência do empregador, que determina a dinâmica da execução do trabalho. A pessoalidade ocorre quando o trabalhador presta de forma pessoal o seu serviço, executando-o presencialmente, sendo vedada a possibilidade de substituir-se por outra pessoa. A onerosidade consiste na contraprestação recebida pelo empregado em face da prestação desse serviço, sendo o pagamento decorrente do labor executado em face ao contrato pactuado entre as partes. A 
habitualidade ocorrerá quando houver a presença continuada do empregado no local de trabalho, ou seja, o labor deve ser prestado de forma contínua e permanente, pois somente assim a habitualidade restará caracterizada.

Na pejotização, tenta-se descaracterizar o vínculo empregatício ao impor ao trabalhador, como requisito para sua contratação, a obtenção da condição de pessoa jurídica. Pretende-se com esta “prestação de serviço” fazer parecer que o contrato ocorreu entre duas empresas, inexistindo o vínculo de emprego e consequentes encargos a ele relacionados. Todavia, a execução do trabalho e a dinâmica de como ele ocorre acabam "desmascarando" o contrato de prestação de serviço e caracterizando o contrato de trabalho, já que, na prestação do labor, encontram-se presentes os requisitos essenciais previstos pelo art. $3^{\circ}$ da CLT, já mencionados.

Os dados quantitativos demonstram que, no ano de 2010, das oito decisões encontradas, em seis delas o julgador afirmou perceber movimentos, por parte da empresa, de tentativa de desconfiguração do contrato de trabalho. Assim, consoante os índices da pesquisa, 75\% dos julgadores em 2010 entendeu que estava configurado o vínculo empregatício. No ano de 2011, das 11 decisões encontradas, em seis delas identificou-se o vínculo empregatício, o que equivale a 54\%. No ano de 2012, das 14 decisões encontradas, em oito delas identificou-se o vínculo empregatício, equivalentes a 57\%. No ano de 2013, das 40 decisões encontradas, em 27 delas identificou-se o vínculo empregatício - 67\%. No ano de 2014, das 46 decisões encontradas, em 25 delas identificouse o vínculo empregatício, o que equivale a 54\%. No ano de 2015, das 81 decisões encontradas, em 45 delas identificou-se o vínculo empregatício, o que corresponde a 55\%. No ano de 2016, das 110 decisões encontradas, em 50 delas, ou 45\%, identificou-se o vínculo empregatício. No ano de 2017, das 88 decisões encontradas, em 62 delas - 70\% - identificou-se o vínculo empregatício.

Em dados finais comparativos entre os anos de 2010 e 2017, temos a seguinte ilustração gráfica (Gráfico 1): 
Gráfico 1 - Configuração do vínculo empregatício

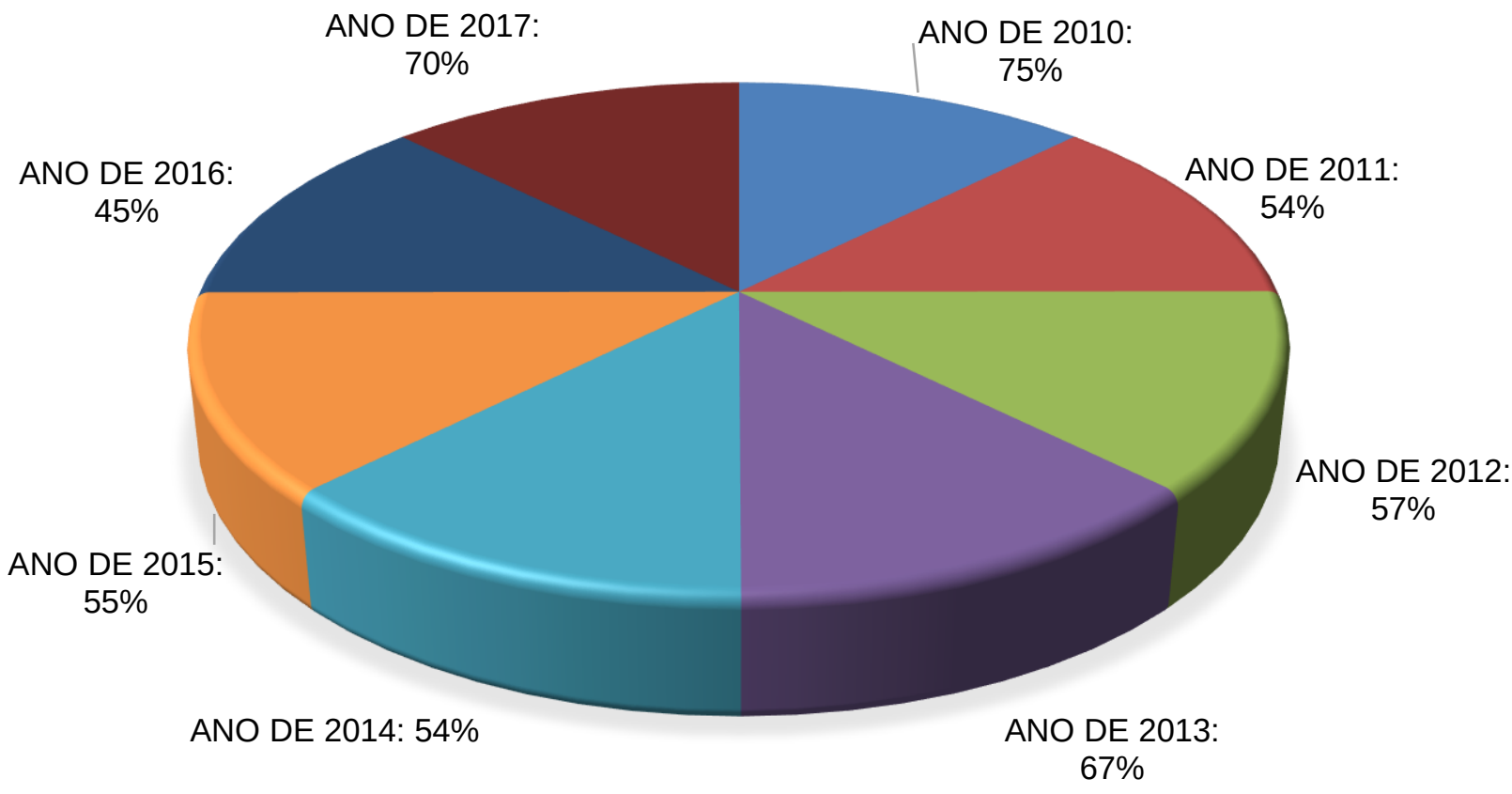

Fonte: os autores.

Assim, consoante as decisões judiciais coletadas no TRT-1, a contratação pejotizada tende ainda a ser percebida como uma prática ilegal no âmbito do Tribunal. Porém, observa-se que entre 2010 e 2017 houve uma redução do percentual de julgados em que se reconheceu a pejotização como uma prática ilegal com base na configuração de vínculo empregatício, com oscilações entre os anos.

\subsection{APLICAÇÃO DO PRINCÍPIO DA PRIMAZIA DA REALIDADE}

As decisões judiciais têm invocado em sua fundamentação o princípio da primazia da realidade, princípio este que norteia as relações laborais e que estabelece que, havendo discordância entre aquilo que acontece na prática e aquilo que advém de documentos ou neles se encontra, devese priorizar o que ocorre no plano da realidade. Esse princípio é um dos que se destinam a proporcionar o equilíbrio na relação entre empregador e empregado, pois privilegia os fatos que se sucedem no cotidiano laboral e não naquilo que está formalmente escrito no contrato. Em outros termos, o magistrado desconsidera a “pessoa jurídica”, para viabilizar que o trabalhador tenha acesso 
aos seus direitos trabalhistas, beneficiando também o órgão estatal, que passará então a receber os pagamentos referentes à previdência, assim como os demais encargos sociais devidos.

Os julgadores têm aplicado esse princípio como um argumento a mais para fundamentar suas decisões. Nele é recomendado que a realidade dos fatos seja mais valorizada do que o que está escrito, devendo ser mais relevante aquilo que ocorre na realidade, e não o lado formal do pacto.

Os dados quantitativos demonstram que, no ano de 2010, das oito decisões encontradas, em duas delas invocou-se o princípio da primazia da realidade como argumento para caracterização do contrato de trabalho na pejotização, o que equivale a 25\% das decisões. No ano de 2011, das 11 decisões encontradas, em três delas invocou-se esse princípio, o que representa $27 \%$. No ano de 2012, das 14 decisões encontradas, em quatro delas invocou-se esse princípio, o que corresponde a 28\%. No ano de 2013, das 40 decisões encontradas, em 18 delas houve a invocação desse princípio, correspondentes a 45\%. No ano de 2014, das 46 decisões encontradas, em 10 delas esse princípio foi invocado, o que equivale a 21\%. No ano de 2015, das 81 decisões encontradas, em 20 delas esse princípio foi invocado como argumento para caracterização do contrato de trabalho, o que significa 24\%. No ano de 2016, das 110 decisões encontradas, em 35 delas invocou-se esse princípio, o que equivale a 31\%. No ano de 2017, das 88 decisões encontradas, em 31 delas, equivalentes a 35\%, invocou-se esse princípio.

Em dados finais comparativos entre os anos de 2010 e 2017 temos a seguinte ilustração gráfica para esta categoria (Gráfico 2): 
Gráfico 2 - Aplicação do princípio da primazia da realidade



Fonte: os autores.

Assim, consoante as decisões judiciais coletadas no TRT-1, a contratação pejotizada tende ainda a ser percebida como uma prática ilegal no âmbito do Tribunal. Observa-se que entre 2010 e 2017 houve um aumento do percentual de julgados que reconheceu a pejotização como uma prática ilegal com base no princípio da primazia da realidade, com oscilações entre os anos.

\subsection{VULNERABILIDADE DO TRABALHADOR}

A vulnerabilidade do trabalhador se verifica pela falta de igualdade econômica e, algumas vezes, intelectual para pactuar e estabelecer acordos com o empregador. Mesmo que o trabalhador seja "esclarecido", diante da sua vulnerabilidade financeira e da necessidade de empregar-se pode acabar aceitando situações desvantajosas a si próprio.

Os julgadores também têm considerado como elemento essencial caracterizador da vulnerabilidade do trabalhador algumas questões como, por exemplo, a falta de informação e de conhecimento mínimo da lei, certa inocência e submissão decorrente da mínima instrução e exclusão digital.

Assim, conforme se verifica, certas relações trabalhistas apresentam este perfil, em que a vulnerabilidade do empregado surge em face da sua hipossuficiência, necessidade e todas as demais 
questões descritas, o que impulsiona aquele que detém maior poder econômico a tentar se beneficiar, com a pejotização, dessa realidade. Em outros termos, por ter uma condição de força econômica inferior à do seu contratante, o empregado acaba por sujeitar-se à imposição patronal, mesmo sabendo que, se não buscar a proteção jurisdicional ao término do contrato, estará excluído do ambiente de proteção do direito trabalhista.

Os dados quantitativos demonstram que, no ano de 2010, das oito decisões encontradas, em uma delas, o que equivale a $12 \%$, os julgadores entenderam que o empregador buscou se beneficiar da vulnerabilidade do trabalhador a fim de atender como prioritários os próprios interesses da empresa, mediante a obtenção de menos gastos com o empregado. Já no ano de 2011, das 11 decisões encontradas, em três delas (27\%) os julgadores entenderam que o empregador buscou se beneficiar da vulnerabilidade do trabalhador nas contratações pejotizadas. No ano de 2012, das 14 decisões encontradas, em sete delas (50\%) os julgadores entenderam que o empregador buscou se beneficiar dessa vulnerabilidade. No ano de 2013, das 40 decisões encontradas, em 18 delas (45\%) os julgadores entenderam haver exploração dessa vulnerabilidade. Já no ano de 2014, das 46 decisões encontradas, em nove delas os julgadores entenderam que o empregador procurou se valer dessa vulnerabilidade, o que equivale a 19\%. No ano de 2015, das 81 decisões encontradas, em 42 delas (51\%) os julgadores entenderam que o empregador buscou se beneficiar da vulnerabilidade do trabalhador pejotizado. No ano de 2016, das 110 decisões encontradas, em 35 delas (31\%) os julgadores entenderam que o empregador intentou se beneficiar dessa vulnerabilidade do trabalhador. No ano de 2017, das 88 decisões encontradas, em 30 delas (34\%) os julgadores entenderam que o empregador buscou explorar a situação de vulnerabilidade do trabalhador nas contratações pejotizadas.

Em dados finais comparativos entre os anos de 2010 a 2017 temos os seguintes resultados para esta categoria (vulnerabilidade do trabalhador), assim ilustrada (Gráfico 3): 
Gráfico 3 - Vulnerabilidade do trabalhador

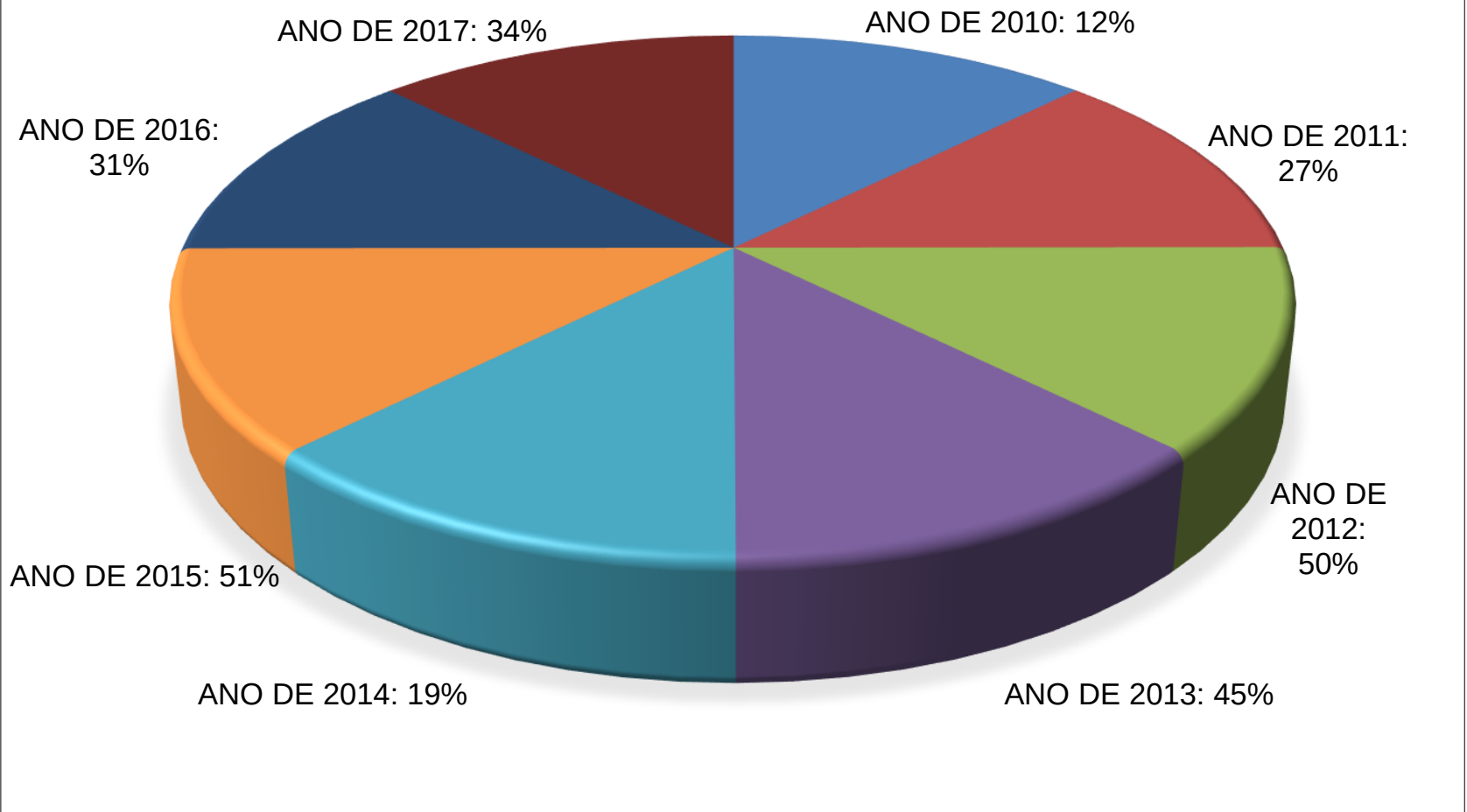

Fonte: os autores.

Assim, consoante as decisões judiciais coletadas no TRT-1, a contratação pejotizada tende ainda a ser percebida como uma prática ilegal no âmbito do Tribunal. Observa-se que entre 2010 e 2017 houve um aumento do percentual de julgados que reconheceu a pejotização como uma prática ilegal com base na vulnerabilidade do trabalhador, com oscilações entre os anos.

\subsection{CARACTERIZAÇÃO DA FRAUDE TRABALHISTA}

As decisões do TRT-1 têm considerado que a admissão de um trabalhador como pessoa jurídica é fraudulenta, uma vez que proporciona ao empregador a vantagem da diminuição dos encargos sociais a que estaria obrigado, referentes à contratação do empregado. Em outros termos, o maior objetivo do empregador seria a redução dos custos que teria que arcar com a mão de obra contratada. O trabalhador, segundo as decisões do TRT-1, amarga prejuízos ainda maiores, pois a pejotização retira-lhe direitos legalmente assegurados, tais como as verbas contratuais e também rescisórias, além dos benefícios comuns ao empregado legalmente contratado, como limitação da carga horária de trabalho e possíveis garantias de emprego.

Os julgadores têm argumentado que, se caracterizados os requisitos essenciais para o vínculo de emprego, reconhecê-lo é o primeiro procedimento a ser adotado, já que a fraude restará provada. 
Argumentam também que a fraude ocorrida por meio da pejotização somente comprova o esforço do empregador em “mascarar” a real relação empregatícia.

Assim, conforme entendimento do TRT-1, é reprovável a tentativa de falseamento do contexto real em que se pretende “mascarar” de pessoa jurídica a pessoa física, pois, no desenvolver da atividade, as regras serão hierarquicamente determinadas pelo empregador. Vale lembrar que as decisões mencionam que o empregador permanece com o comando, direção e gerência da prestação do serviço.

Os dados quantitativos demonstram que, no ano de 2010, das oito decisões encontradas, em três delas (37\%) os julgadores entenderam que havia caracterização de fraude. No ano de 2011, das 11 decisões encontradas, em quatro delas (36\%) os julgadores entenderam que havia essa caracterização. No ano de 2012, das 14 decisões encontradas, em sete delas (50\%) os julgadores vislumbraram essa caracterização. No ano de 2013, das 40 decisões encontradas, em 25 delas (62\%) os julgadores entenderam haver ocorrência de fraude. No ano de 2014, das 46 decisões encontradas, em 12 delas (26\%) os julgadores entenderam pela mesma caracterização de fraude. No ano de 2015, das 81 decisões encontradas, em 33 delas (40\%) os julgadores entenderam no mesmo sentido de fraude. No ano de 2016, das 110 decisões encontradas, em 35 delas (31\%) os julgadores entenderam que houve caracterização de fraude. No ano de 2017, das 88 decisões encontradas, em 38 delas (43\%) os julgadores entenderam ter havido essa caracterização.

Em dados finais comparativos entre os anos de 2010 e 2017 temos os seguintes resultados para esta categoria (caracterização da fraude trabalhista), abaixo ilustrada (Gráfico 4): 


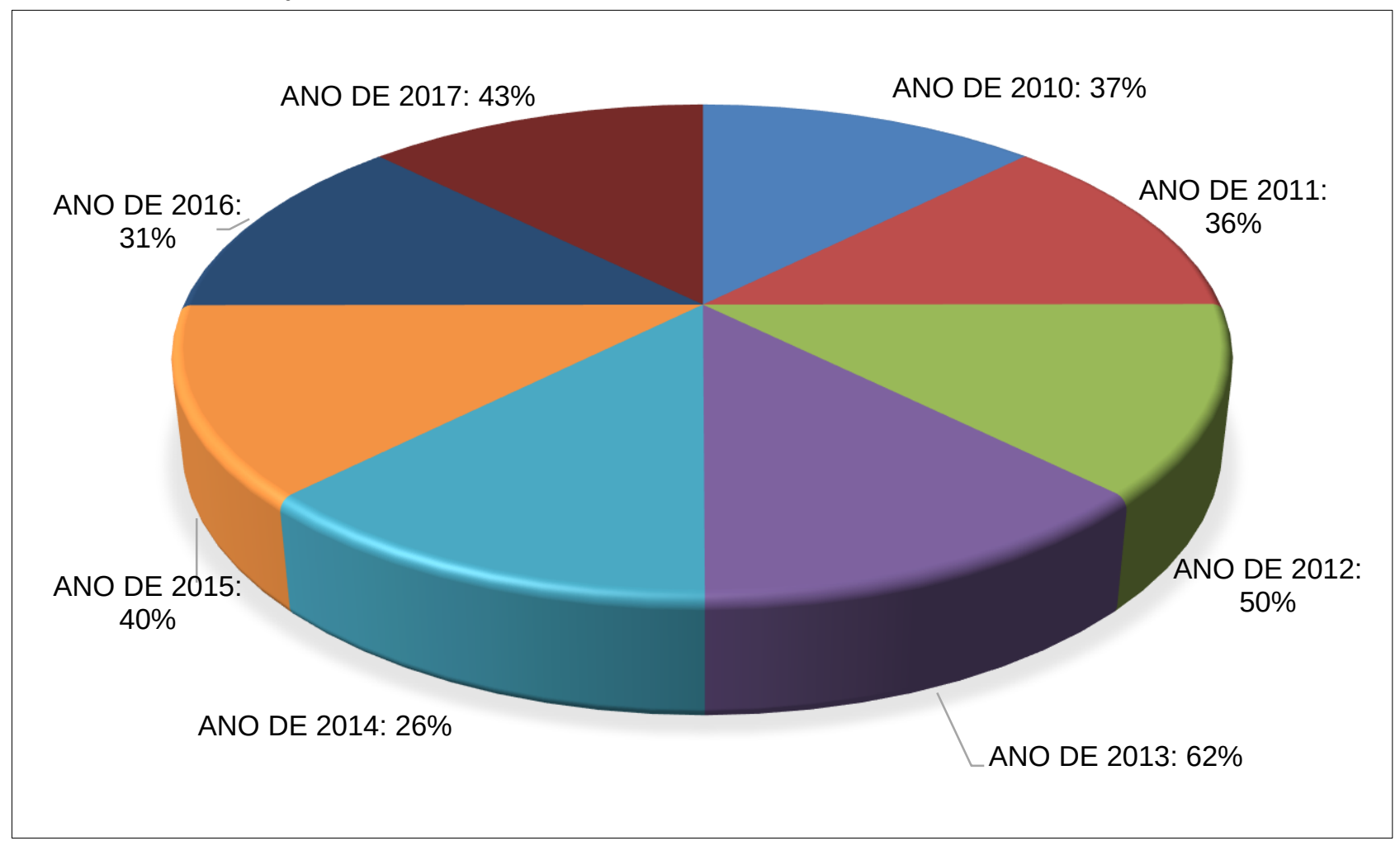

Fonte: os autores.

Assim, consoante as decisões judiciais coletadas no TRT-1, a contratação pejotizada tende ainda a ser percebida como uma prática ilegal no âmbito do Tribunal. Observa-se que entre 2010 e 2017 houve um aumento do percentual de julgados que reconheceu a pejotização como uma prática ilegal com base na caracterização de fraude trabalhista, com oscilações entre os anos.

Por fim, vale citar que no contexto geral analisado, além das quatro categorias já descritas, encontramos 37 decisões nas quais a pejotização não foi configurada, oito decisões nas quais se invocou o princípio da irrenunciabilidade (os direitos trabalhistas são irrenunciáveis) e 35 decisões nas quais o julgador focou na análise de outras razões processuais (embargos, cerceamento de defesa, coisa julgada, suspeição de testemunha, ausência de recolhimento de custas, etc.).

\subsection{COMPARAÇÃO ENTRE OS DADOS DA PRÉ-REFORMA E DA PÓS-REFORMA TRABALHISTA}

Antes de a Reforma Trabalhista ser instituída, as decisões do TRT-1 entre o período de 2010 a 2017 se posicionavam majoritariamente contrárias à pejotização. Para tanto, invocavam-se os requisitos caracterizadores da relação de trabalho (subordinação, pessoalidade, onerosidade e habitualidade) e havia o argumento de que nas contratações pejotizadas o contratado ficava submetido 
às ordens do contratante, executando seu labor de forma pessoal e habitual. O gráfico a seguir ilustra bem esta posição, senão vejamos (Gráfico 5):

Gráfico 5 - Anos 2010 a 2017: universo de 402 decisões

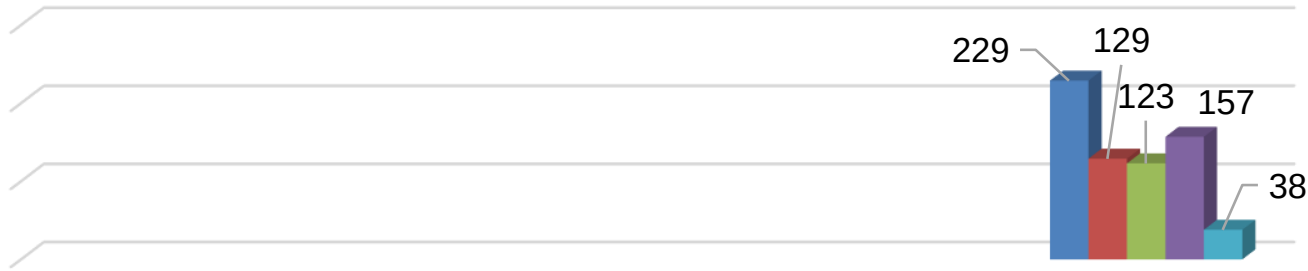

- Configuração do Vínculo

- Vulnerabilidade do Trabalhador

- Aplicação do Princípio da Primazia da Realidade

- Caracterização da Fraude Trabalhista

- Pejotização não caracterizada

Fonte: os autores.

Com o advento da Reforma, é notório que foram realizadas diversas modificações na legislação trabalhista, inclusive quanto à pejotização, motivo pelo qual se levantaram muitas discussões e debates sobre a eventual mudança no posicionamento dos Tribunais.

A Reforma buscou legitimar a contratação pejotizada equiparando-a à contratação de profissional autônomo. O autônomo é aquele que executa o seu labor por conta própria e que assume por si os riscos do seu ofício. Na prática, é o próprio profissional que estabelece a maneira e o local onde executará a sua atividade laborativa. $\mathrm{O}$ autônomo tem essa liberdade e independência, pois não há subordinação jurídica na relação contratual, haja vista que a execução do labor ocorre de maneira eventual, inexistindo também a habitualidade. O autônomo usufrui da prerrogativa de desenvolver seu labor por meio de organização, livre escolha e iniciativa própria, podendo selecionar o modo, o lugar e a maneira de laborar, bem como o tempo que será despendido para isso. O profissional autônomo é aquele que explora a própria força laborativa em seu proveito, obtendo benefícios, mas também suportando os riscos inerentes à sua condição. 
Mais precisamente, a Reforma criou a figura do "autônomo exclusivo", a fim de tornar legítima a pejotização. Segundo o novo texto legal, este profissional presta o seu labor de maneira contínua para uma única empresa, sem que isso caracterize vínculo empregatício, mesmo quando o autônomo exclusivo executa o seu labor de forma contínua. Ainda assim, estará afastada a condição de empregado prevista pelo art. $3^{\circ}$ da CLT.

Resta claro que o legislador pretendeu excluir alguns dos requisitos que configuram a relação de trabalho - subordinação jurídica e habitualidade -, pois a prestação do serviço poderá ser contínua ou não. Com a instituição do “autônomo exclusivo”, pretendeu-se facilitar a pejotização, afastando, para tanto, a qualidade de empregado determinada pelo artigo $3^{\circ}$ da CLT.

Com este dispositivo, a Reforma Trabalhista descaracterizou a subordinação jurídica na contratação pejotizada. Em decorrência desta inovação, surgiram diversas conjecturas que afirmam que a pejotização tornou-se legalmente possível, bastando contratar o indivíduo como autônomo, em vez de empregado. A diferença que há entre um empregado comum e um trabalhador autônomo é que o autônomo executa o seu serviço livre do cumprimento de ordens de outrem, livre do cumprimento de jornada e usufruindo ainda da prerrogativa de se fazer substituir por outra pessoa, uma vez que goza de autonomia. O trabalhador comum, por sua vez, é submetido a ordens de outrem (subordinação), executa o seu labor de forma pessoal (pessoalidade) e é submetido a uma jornada pré-determinada, tudo isso mediante subordinação.

Na pesquisa realizada, foram analisadas as 20 primeiras decisões do ano de 2018 que aparecem nos resultados de busca do site do TRT-1, já que a Reforma passou a viger em 11 de novembro de 2017. Vale mencionar que não foi encontrada nenhuma decisão sobre o tema entre o período de 11 de novembro de 2018 e até o recesso judiciário do fim desse ano. Assim, para que a comparação se tornasse possível, utilizou-se de 20 decisões do ano de 2018 para análise.

Na prática, o que se tem considerado pela leitura dessas decisões pós-Reforma é que o julgador mantém o mesmo entendimento de antes. Das 20 decisões analisadas, em 19 delas decidiuse pela configuração do vínculo; em 10 delas considerou-se a vulnerabilidade do trabalhador; em oito delas invocou-se o princípio da primazia da realidade como fundamento; em 18 delas identificou-se a tentativa de fraude à lei trabalhista; e, somente em duas delas, a pejotização não foi caracterizada.

Observou-se também que o julgador tem utilizado com mais frequência o argumento da subordinação estrutural ou integrativa. Quando o julgador observou que havia alguma forma de controle do trabalho do autônomo ou subordinação estrutural ou integrativa, reconheceu o vínculo empregatício e a ilegalidade da pejotização. Os julgadores argumentaram que a subordinação estrutural ou integrativa ocorreria quando a execução do serviço do trabalhador fosse ao encontro da 
atividade da empresa, ou seja, quando o seu ofício fosse fundamental à atividade empresarial, integrando, para tanto, o processo produtivo do patrão ou estando em consonância com a dinâmica estrutural de funcionamento da contratante. Em outros termos, a atividade exercida pelo empregado precisaria ter ligação com os objetivos da empresa, estando unida a atividade principal dela, o que faria do empregado um subordinado integrativo e configuraria o vínculo empregatício. Os julgadores também esclareceram que na subordinação estrutural não seria necessário que o trabalhador estivesse submetido a ordens diretas do contratante para caracterização do vínculo de trabalho, haja vista que estaria integrado ao processo produtivo da empresa.

Neste primeiro momento pós-Reforma, observa-se então o reconhecimento, pelo Tribunal, de que a subordinação jurídica não seria unicamente a tradicional sujeição pessoal. Havendo a dedicação por parte do trabalhador e controle do labor do profissional de idêntica maneira ao dos outros colaboradores, descaracterizada estaria a autonomia e configurado o vínculo empregatício.

Dentro deste período histórico analisado, a jurisprudência do TRT-1 não teve mudanças significativas após a Reforma. Segundo os dados, a pejotização não se tornou possível e muito menos legal com o advento da Reforma Trabalhista, pois continuaria sendo uma modalidade de contratação ilegal que violaria direitos trabalhistas inerentes ao contrato de trabalho previstos pela CLT, segundo o Tribunal.

\section{CONSIDERAÇÕES FINAIS}

Como visto, a pejotização ocorre quando o empregador condiciona a contratação do empregado à constituição de uma pessoa jurídica, ou seja, a um “contrato de prestação de serviços” entre duas PJ (o contratante e o contratado). Essa prática se tornou muito comum no âmbito das contratações trabalhistas, já que por meio dela libera-se o empregador do pagamento de encargos sociais e trabalhistas que são inerentes à contratação do empregado.

Embora os direitos trabalhistas sejam irrenunciáveis, a contratação pejotizada tem sido vista na jurisprudência do TRT-1 como uma forma de "mascarar" o contrato de trabalho que, na prática, existiria. Com isso, os julgados vêm declarando nulo esses contratos de prestação de serviço e reconhecendo o vínculo empregatício nas contratações pejotizadas.

A Reforma Trabalhista empenhou-se em facilitar a contratação via PJ. Todavia, esse “incentivo” promovido pela Reforma, segundo a jurisprudência do TRT-1 no período pesquisado, suprime direitos e enfraquece os direitos sociais. 
Mediante a análise dos julgados, restou esclarecido que a maioria das decisões pré- e pósReforma declara que a pejotização é uma contratação ilegal e prejudicial ao trabalhador. Observouse a afirmação dos julgadores de que a pejotização afrontaria o princípio da primazia da realidade, que determina que deve prevalecer o que ocorre na prática e não o que está escrito. Observou-se também que a pejotização tentaria desconfigurar o vínculo empregatício, cabendo ao empregador o dever de pagamento de todas as verbas suprimidas no decurso do tempo laborado. Observou-se ainda a assunção de que não adiantaria o contratante impor ou sugerir ao contratado a constituição de pessoa jurídica enquanto requisito para a contratação propriamente dita, pois permaneceria a ilegalidade.

À vista disso, segundo a jurisprudência do TRT-1, a pejotização seria uma modalidade de contratação ilegal, já que afrontaria o princípio da primazia da realidade e se aproveitaria da vulnerabilidade do empregado. Seria, então, uma fraude às relações de trabalho violadora dos direitos sociais versados na Constituição de 1988. O TRT-1 tem buscado meios para reconhecimento do vínculo, tais como os argumentos da subordinação estrutural, do princípio da primazia da realidade, do princípio da vulnerabilidade do empregado e do reconhecimento de fraude trabalhista.

Trata-se de dados importantes para a discussão sobre a Reforma Trabalhista, que deverão ser aprofundados e novamente coletados em pesquisas que busquem monitorar as tendências decisórias dos tribunais e uma comparação entre os períodos pré- e pós-Reforma.

\section{REFERÊNCIAS}

ASENSI, Felipe Dutra; AIDAR, Adriana; RAMOS, Frederico; PINHEIRO, Roseni. Judicialização, direito à saúde e prevenção. RECIIS - Revista Eletrônica de Comunicação, Informação e Inovação em Saúde, vol. 9, n. 01, 2015.

BARROS, Alice Monteiro de. Curso de direito do trabalho. São Paulo: LTr, 2015.

DALLARI, Sueli; BARBER-MADDEN, Rosemary; FERNANDES, Marília; SHUQAIR, Nur; WATANABE, Helena. A Advocacia em saúde no Brasil contemporâneo. Revista de Saúde Pública, vol. 30, nº 6, 1996.

MANDL, Alexandre Tortorella. A judicialização dos conflitos coletivos de trabalho: uma análise das greves julgadas pelo TST nos anos 2000. Revista da ABET, v. 13, n. 2, 2014.

MARCONDES, Fernanda Marchi; NAOMI, Isabella Akiyama. O fenômeno da Pejotização e suas conseqüências nas relações de emprego. Jusbrasil. 25 dez. 2015. Disponível em: https://bit.ly/2IBHxsd. Acesso em: 8 jan. 2018.

REALE, Miguel. Lições preliminares de direito. São Paulo: Saraiva, 2011. 
TATE, Neal; VALLINDER, Tobjörn. The global expansion of judicial power. New York: New York University Press, 1995.

TAYLOR, Matthew. O judiciário e as políticas públicas no Brasil. Dados - Revista de Ciências Sociais, vol. 50, nº. 2, pp. 229-257, 2007.

VIANNA, Luiz Werneck. Apresentação. In: VIANNA, Luiz Werneck (org.). A democracia e os Três Poderes no Brasil. Belo Horizonte: Editora UFMG, 2003.

VIANNA, Luiz Werneck; BURGOS, Marcelo; SALLES, Paula. Dezessete anos de judicialização da política. Cadernos CEDES, 2006.

VIANNA, Luiz Werneck; CARVALHO, Maria Alice Rezende de; MELO, Manuel Palácios Cunha; BURGOS, Marcelo Baumann. Judicialização da política e das relações sociais no Brasil. Rio de Janeiro: Revan, 1999.

Felipe Dutra Asensi

Pós-Doutor em Direito pela Universidade do Estado do Rio de Janeiro (UERJ). Doutor em Sociologia pelo Instituto de Estudos Sociais e Políticos (IESP/UERJ). Mestre em Sociologia pelo Instituto Universitário de Pesquisas do Rio de Janeiro (IUPERJ). Advogado formado pela Universidade Federal Fluminense (UFF). Cientista Social formado pela Universidade do Estado do Rio de Janeiro (UERJ). Aperfeiçoamento em Direitos Fundamentais pela Universidad Complutense de Madrid (UCM), em Empreendedorismo pela University of Maryland (UM) e em Coaching pela University of Cambridge (UCA). Professor visitante da Fundación Universitaria Los Libertadores (FUL). Foi Visiting Scholar da Universidade de Coimbra (UC). Membro da Comissão Tutorial do Programa Internacional Erasmus Mundus (União Européia). Membro vitalício da Academia Luso-Brasileira de Ciências Jurídicas (ALBCJ). Membro Efetivo do Conselho Internacional de Altos Estudos em Direito (CAEDJus). Membro Efetivo do Instituto dos Advogados Brasileiros (IAB). Senior Member da Inter-American Bar Association (IABA). Membro Benemérito do Instituto LatinoAmericano de Argumentação Jurídica (ILAAJ). Membro do Comitê Consultivo Nacional da Biblioteca Virtual de Saúde (BVS-Integralidade). Membro Titular da Red Iberoamericana de Derecho Sanitario (RIDS). Membro do Conselho Curador do PenseSUS (Fiocruz). Membro da Asociación Latinoamericana de Sociología (ALAS). Professor de Mestrado/Doutorado da Universidade do Estado do Rio de Janeiro, Universidade Católica de Petrópolis e Universidade Santa Úrsula. Professor convidado da FGV, PUC, IBMEC e Ambra College (EUA). Editor Adjunto da Coleção Integralidade na CEPESC Editora. Presidente do Conselho Editorial da Editora Ágora21. Presidente da Comissão de Gestão Jurídica da OABRJ. Diretor do Instituto Diálogo. Diretor administrativo do Centro de Estudos e Pesquisa em Saúde Coletiva (CEPESC). Consultor para o Brasil do World Justice Report. Manager of Legal Research and Teaching do Master of Science in Legal Studies da Ambra College (EUA). Bolsista de Produtividade Jovem Cientista do Nosso Estado da Fundação de Amparo à Pesquisa do Estado do Rio de Janeiro (FAPERJ) e Bolsista de Produtividade Desenvolvimento Acadêmico e Tecnológico do Centro de Estudos e Pesquisa em Saúde Coletiva (CEPESC).E-mail: felipedml@yahoo.com.br

Isabela Pfister Gonçalves Possui graduação em Direito pela Universidade do Grande Rio. Pós-Graduada em Gestão Executiva em Meio Ambiente pela Universidade Federal do Rio de Janeiro; Pós-Graduada em Direito Público pela Universidade Gama Filho. Possui curso de Extensão em Aperfeiçoamento em Gestão Ambiental dos Recursos Hídricos pela UERJ. Mestre em Gestão do Trabalho para a qualidade do Ambiente construído. Pesquisador jurídico - J. J. Machado Advocacia.E-mail: pfister@oi.com.br 